\title{
Organ transplant initiatives: the twilight zone
}

\author{
David P T Price School of Law, De Montfort University, Leicester.
}

\begin{abstract}
Assessments of the acceptability of new transplantation practices require a pinpointing of not only the meaning of death, but also the timing of death. They typically perceive elective ventilation as occurring just prior to death and non-heart-beating donor protocols as operative just after death. However, such practices in fact highlight the general vagueness and ambiguity surrounding these issues in both law and ethics. Supply-side dilemmas in transplantation lend real urgency to this "life or death" debate.
\end{abstract}

Despite increasing transplantation rates, waiting lists continue to grow for all organs, almost universally. In the UK as of 31.8.96 there were 5,297 patients on the kidney, 305 on the heart and 157 patients on the liver transplant waiting lists. Two procedures which minimise warm ischaemia time affecting the viability of organs for transplantation with clear potential to significantly increase donation rates, "Elective Ventilation" (EV) and "Non-Heart-Beating Donor" (NHBD) protocols, have both, however, been subjected to recent and urgent ethical and legal review.

\section{The new initiatives}

In 1988 the Royal Devon and Exeter Hospital became the first British hospital to develop an EV protocol. ${ }^{1}$ Patients in deep irreversible coma and believed to be dying imminently of intracranial haemorrhage were transferred to intensive care, with relatives' consent, so that artificial ventilation could be commenced immediately respiratory arrest occurred and until brain (stem) death tests could be satisfied. However, in October 1994, the Health Departments of England and Wales issued guidelines stating that EV for transplantation purposes constituted an unlawful battery - being non-therapeutic and not done in the best interests of the individual. $^{2}$ This mirrored the conclusion of the 1994 King's Fund Institute Report ${ }^{2}$ (which none the less endorsed EV as an ethically acceptable practice, as

\section{Key words}

Organ transplants; death; brain death; elective ventilation; non-heart-beating donors. incidentally have the BMA and the Brition Transplantation Society), and is probably an accurate perception of the present common law. Although an alternative "not against the interests of the individual" test has been occasionally employed in relation to non-therapeutic procedures performed on minors, such a standard has yet to be legafity employed in respect of a mentally incompetent ad ât person in a similar context. In the $1980 \mathrm{~s}$, ney NHBD protocols were also implemented, of tw distinct types. The pre-eminent example of the first is the University of Pittsburgh Medical Center protocol, under which patients with profound bratn damage are gradually removed from ventilato $\bar{y}$ y support, with relatives' or patients' consent, ahd their organs removed after death is pronouncel. Similar protocols have been in operation at the King's College Hospital, Dulwich and in Zurich. The second type involves the perfusion and coolimg of organs in situ, or whole body cooling, immediately following death and prior to subsequent organ removal. Such protocols are in operation in Britalin

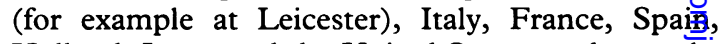
Holland, Japan and the United States, and are substantially on the increase worldwide. These are typhcally temporary measures initiated to allow sufficient time for authorisation for organ donation to Be obtained. By contrast with EV, NHBD protocols by no means new. Not only did they antedate the us of heart-beating donors, they have been in consistegpt use in countries, for example, Japan, that have yot fully to embrace the concept of brain death.

There has generally been an easy assumption that patients subject to EV are alive whilst NHBDs arge dead - although the Pittsburgh protocol has attracted some criticism on this issue. I sh⿻日禸 question these assumptions here - the other centrgl ethical issues surrounding these protocols are dब्Ecussed elsewhere, ${ }^{3}$ including this journal. ${ }^{4}$ The d产cussion highlights the vagueness and ambiguity $\frac{\pi}{\mathrm{w}}$ the legal meaning of death, in this jurisdiction agid elsewhere, as well as what criteria/evidence needs to be established in order to determine that death hâs occurred and when precisely death occurs. As is consistently the case, transplantation practices briong these issues into atypically sharp relief. 


\section{The legal meaning of death}

Commentators who assert that in English law death is brain stem death are rather too dogmatic. Although brain (stem) death, established according to accepted medical criteria, is death in this country and most other countries, English law is vague as to whether death is only brain death, as established by the criteria of either brain stem death or the (irreversible) cessation of cardiopulmonary activity, or whether, alternatively, it is either brain stem death or the (irreversible) cessation of cardiopulmonary activity?

In three recent cases the courts decided that a brain stem dead patient is dead for legal as well as medical purposes, Mail Newspapers $v$ Express Newspapers, ${ }^{5} \operatorname{Re} A$ (A Minor) ${ }^{6}$ and Airedale NHS Trust $v$ Bland. $^{7}$ In the first two cases, the High Court decided simply that the brain stem dead patient was dead. In Bland the House of Lords decided that Tony Bland was not dead - his brain stem was still functioning despite his PVS condition. However, although Lord Keith explicitly stated that "In the eyes of the medical world and of the law a person is not clinically dead so long as the brain stem retains its function" (a view of the medical world not wholly borne out by the practices described in this paper!), this was not a central facet of the decision and not binding on future courts (an obiter dictum), as he could not have been adjudged dead according to any other criteria as his heart continued to pump and his lungs to carry out gas exchange. In most of the US states (adopting the Uniform Determination of Death Act 1980) and the Australian states and territories, irreversible cardiopulmonary failure is explicitly stipulated by legislation to be an alternative legal standard of death. In Britain this may well also be so, despite the absence of any recent authoritative and explicit legal statement to this effect.

\section{The meaning of death}

\section{ELECTIVE VENTILATION}

By contrast with the majority view across all disciplines, the clinicians who developed the Exeter protocol argue that the process of dying is not prolonged by $\mathrm{EV}$, as the patient is already dead - one is ventilating a corpse. The basic disagreement here might seem to be founded on a dispute as to the meaning of death itself, whereas this is not in fact so, only brain death is in issue - it is not possible to rely on traditional cardiopulmonary criteria when the natural functioning of the heart and lungs is obscured by the intervention of the ventilator. Moreover, the clinicians themselves do not purport to be relying on "cardiopulmonary death". Riad, from Exeter, has said "The procedure causes no harm to the patient as ventilation is instituted at the time of respiratory arrest which is the consequence of brain death. . . . Therefore it is important not to institute EV before respiratory arrest". ${ }^{8}$ Such a sequence of events is explicitly referred to in the Memorandum on the Diagnosis of Death attached to Cadaveric Organs for Transplantation (1983) issued by the Conference of the Medical Royal Colleges: "In a minority of cases, brain death does not occur as a result of the failure of other organs or systems but as a direct result of severe damage to the brain itself from, perhaps, a head injury or a spontaneous intracranial haemorrhage. Here the order of events is reversed: instead of the failure of such vital functions as heart beat and respiration eventually resulting in brain death, brain death results in the cessation of spontaneous respiration: this is normally followed within minutes by cardiac arrest due to hypoxia. If however oxygenation is maintained by artificial ventilation, the heart beat can continue for some days, and haemoperfusion will for a time be adequate to maintain function in other organs, such as the liver and kidneys". ${ }^{9}$ Supporters of the Exeter protocol argue that cessation of respiration is (necessary and sufficient) evidence that the patient has already succumbed to brain death - the question is whether this is so.

\section{NON-HEART-BEATING DONORS}

Under the Pittsburgh protocol, organs are removed immediately the patient is shown to be apnoeic and unresponsive for two minutes to one of three electrocardiographic criteria, ie ventricular fibrillation, electric asystole or electromechanical dissociation. ${ }^{10}$ Typically though, the medical literature describing NHBD protocols is less than full and explicit as to how and when death is determined according to cardiopulmonary criteria. In Tokyo, cooling in situ is commenced "immediately after cardiac arrest", whilst at King's College, Dulwich organs are removed "up to 45 minutes after the heart has stopped beating". Unlike EV, NHBD protocols involve a choice between competing concepts of death, not just varying criteria for the same concept of death. As Mason and McCall Smith state, "If we are to accept the concept of 'brain death' as argued below, we should treat the person in irreversible cardiorespiratory failure as dying rather than dead - for the true agonal period in natural death is that which lies between cardiac arrest and cerebral failure". ${ }^{11}$ According to this perspective, failures of respiration and heartbeat are relevant only because they will lead, in some cases, to death.

The primary reliance under NHBD protocols is upon irreversible loss of cardiopulmonary function as the standard of death, not simply as evidence of brain death. It is well known that the brain stem (and a fortior the whole brain) will only cease to function after loss of cardiac function and oxygen deprivation lasting for some minutes - certainly more than the two minutes stipulated by the Pittsburgh protocol. But even assuming that there is an independent alternative cardiopulmonary standard of death, it is not clear that such patients are dead even according to this standard. The primary problem here is the 
difficulty in establishing that the cessation of respiration and heartbeat was irreversible - which is an explicit and invariable legislative stipulation. For many, two minutes of asystole is insufficient to establish that spontaneous auto-resuscitation will not occur. In addition, the Pittsburgh protocol excludes the possibility of interventions that could restart the heart (artificial resuscitation is withheld by virtue of the joint decision of doctors and relatives).

\section{A nebulous concept}

But is irreversibility properly a facet of legal or ethical standards of death, and if so, what does it convey? Necessarily, reversibility requires the benefit of some significant degree of hindsight, which such protocols may partially preclude in the quest to preserve the viability of organs for transplantation. However, although reversibility is undoubtedly a nebulous and problematic concept, as has been noted by numerous commentators in this journal, it is not for that, or any other, reason dispensable either legally or ethically. Moreover, the notion of reversibility based upon what is "ethically significant", as suggested by Tomlinson, is dubious. ${ }^{12}$ Our duties to the living may dictate whether someone "will die" but they cannot determine whether a person "is dead" ie whether we could have reversed it, not whether we should have reversed it. Inevitably irreversibility is relative and linked to time and culture, but this is not to say that death is relative as between individuals of the same culture and at the same relevant time.

Cole argues that the notion of irreversibility is superfluous because it is out of line with the "ordinary concept" of death, which is based on the loss of a natural capacity to resume (cardiopulmonary) function, and that consequently such a notion should not form any part of a legal definition of death. ${ }^{13}$ This is surely implausible, since our lives are supported by all manner of non-natural means, some temporary some permanent. None the less, would it not be plausible instead to link the notion of reversibility with the notion of natural functioning? Although we surely would not say that a person was dead simply on account of cardiac arrest when we could restore respiration and circulation by artificial means, we would surely not assert either that all individuals were alive until the point where artificial means could not even cause the lungs to inflate or the blood to circulate? It can be sensibly conceived that a person is dead when the functions of the body are being wholly driven by technology, ie such measures are not even assisting the natural functioning of the body, either temporarily or permanently. At the point where loss of cardiac and respiratory function produces brain stem death the individual ceases to live regardless of extended mechanical "existence" - there is no integrated functioning of the body, and no consciousness, from that moment.
The point of brain death is therefore the criticat point in time whether loss of cardiac function and respiration is an end in itself or only the catalyst for loss of brain function. Catherwood argued in thes journal that "Dying is not an irreversible proces until that process gets to a point where our availab正 technology cannot help". ${ }^{14}$ In so doing he 15 question-begging in using the word "help". Helped to do what? If lung functioning can be mechanicalfy sustained even where the patient has suffered braif stem death, is he/she "helped" or is he/she already dead?

Ironically, although NHBD protocols are explie itly stated to be founded on cardiorespirato criteria, after a certain period of time has elapseid artificial ventilation is applied in many instances a well as cardiac massage. This appears to prove that the cessation was not irreversible. However, in fact this procedure implicitly relies on the notion of irre versibility propounded above. If not, such donors are simply not "non-heart-beating" at all! As it imperative to rely on the death of the brain, the issu is simply what evidence is required to establish that such brain death has occurred. There is ne dichotomy between heart-beating and non-heartbeating donors. Cardiopulmonary cessation evidence of death, not death itself.

\section{The timing of death}

\section{ELECTIVE VENTILATION}

Riad and Nicholls have said "The dilemma is that there is a difference between the diagnosis of death and the timing of death. We believe we ventilate patients at the moment of death, even though we diagnose death only by formal testing for brain stem death some hours later". ${ }^{15}$ The King's Fund Repo also noted that in this context the actual point of death might have been the same (where cessation of respiration precedes brain death and when it occufs as a consequence of brain death), but the point of confirmation of death is not - as the electively ven lated patient is not officially confirmed as being deat until two sets of brain stem death tests have beên performed. Jones, however, has said "Nor can one escape this dilemma by seeking to differentiate between the diagnosis of death and the timing of death. To say that patients are ventilated 'at the moment of death, even though we diagnose dea要 only by formal testing for brain stem death sone hours later' merely shifts the ground as to the 'deter mination' of death. There must be some agrees criteria for determining the moment of death - th $\overrightarrow{g t}$ is, the doctors must have grounds for being able say that 'this patient is dead' and this in itself entaifs a process of diagnosis. It is simply that this diagnosis does not comply with the strict criteria laid down for determining 'formal' brain stem death". ${ }^{16}$ Ti potential dichotomy nevertheless exists between thex. time of death and the diagnosis/confirmation of 
death, although this has no significance in everyday cases. The diagnosis of brain death is in one sense inevitably retrospective, death has already occurred at a point in time which is unknown and unknowable. In the NHBD context, Lynn notes that "Unfortunately, for the proponents of the Pittsburgh protocol, society has never been clear about which point in time . . . will count as the actual time of death. . . . Local practice concerning the time of death to be listed on the death certificate varies when neurologic criteria are used, with some jurisdictions usually using the time at which death was finally able to be declared and others listing the time somewhat earlier when brain function was first documented to have ceased". ${ }^{17}$

\section{Judicial acceptance}

We have observed that although there is no definition of death in English law, brain stem death established in accordance with the agreed criteria incorporated in the code of practice of the medical royal colleges has been accepted as establishing legal as well as "medical" death. However, whilst this constitutes judicial acceptance of these tests, it does not necessarily indicate that this is the sole criterion for the determination of death in law. But what, if any, other evidence of (brain) death would satisfy a court of law? In $\operatorname{Re} A, \mathrm{~A}$, a nineteenmonth-old baby in hospital on a ventilator, was ultimately confirmed by doctors as being brain stem dead after two sets of tests were carried out to confirm this, the first on January 21 and the second on January 22. Johnson J stated: "I have no hesitation at all in holding that $\mathrm{A}$ has been dead since Tuesday of last week, January 21 ". In other words, the time of death was before the second sets of tests were performed to confirm lack of brain stem responses. However, the code of practice states that the time of death should be recorded as the time when death was conclusively established and that "Death is only conclusively established when the criteria have been satisfied on two successive occasions". 9 It appears therefore that the code was not fully adhered to in this instance, nor were the recommendations of the British Paediatric Association, which stipulate that in children older than two months, two sets of tests should be conducted separately by two experienced clinicians 12-24 hours apart. ${ }^{18} \operatorname{Re} A$ illustrates that death can be legally declared to have occurred according to brain death criteria before two sets of tests have been completed and death has been confirmed. Further, in $R v$ Malcharek, $R v$ Steel the court thought that the victims were dead according to either cardiopulmonary criteria or brain stem criteria, despite the fact that two of the brain stem death tests were not performed on one victim and one of the tests was not performed upon the other. ${ }^{19}$ Despite certain views to the contrary, it seems that there is no mandatory legal requirement at present that a person cannot be declared brain (stem) dead unless the recommendations of the report of the medical royal colleges - ie the code of practice - have been complied with in their entirety. The code of practice, although highly influential, does not have the force of law.

Kennedy and Grubb have previously analysed the likely legal position if a patient were declared dead according to brain stem criteria but without the code of practice having been fully adhered to. They believe the answer is contingent upon whether a mistake was made as regards the exclusion of certain pre-conditions (for example, drugs, hypothermia, etc), a failure to perform all the relevant tests, or whether the tests were just not repeated. They are of the opinion that with respect to the first matter the court would simply decide, as a matter of fact, whether the patient was nevertheless dead. On the second issue they state that "We take the view that a court, in the absence of evidence of irresponsible behaviour by the doctor, would be reluctant to find that the patient was not dead at the time asserted". ${ }^{20}$ On the latter issue they suggest that if the tests were confirmatory the courts would be likely to find that the death occurred after the completion of those tests on the first occasion. The cases cited above appear to bear them out. Confirmation is evidence that death has already occurred, reinforcing the dichotomy between the time of death and the date of recording of death. Indeed, the time of confirmation is capable of manipulation for specific ends and therefore should not be invariably tied to the time of death. Although no brain stem death "tests" are seemingly carried out at all prior to EV, a thorough diagnosis of the person's condition is conducted and many of the same contra-indications for brain stem death are ruled out, for example, reversible causes of coma. There must be some possibility that a court would find that an electively ventilated patient was already dead when ventilation was commenced where (i) there was confirmation of the loss of ability for spontaneous respiration and (ii) later performed brain stem death tests proved positive - especially where these were performed almost immediately after the patient was ventilated. However, if one of the concerns is that EV protocols may lead to patients being induced into a PVS state, then certainty regarding the moment of death seems rather dubious - although currently we do not know how great this risk is or whether it is even a true risk at all, because of the moratorium on EV itself.

\section{NON-HEART-BEATING DONORS}

I have argued that death is only brain death but that in any event the important point in time under any standard of death is the point of brain stem death, as only then would cardiorespiratory failure be irreversible. Where brain death follows cardiorespiratory failure a period of time must be agreed upon beyond 
which it is considered that the brain stem cannot have survived. A consensus apparently developed at a recent symposium of transplantation experts in Maastricht, that at least ten minutes should have elapsed without cardiopulmonary function before a potential NHBD is pronounced dead. ${ }^{21}$ The consultants to the President's Commission incidentally also advised that at least ten minutes of proven lack of circulation to the brain was necessary. ${ }^{22}$

\section{Conclusion}

Just as currently brain death is partially linked to the notion of the biological death of the organism, and not just loss of personhood, and a judgment needs to made as to the extent of that biological loss which is compatible with the notion of death, so society must be more decisive as to the level of confidence required to satisfy itself that death has occurred. This in turn requires an a priori judgment as to the meaning or definition of death itself, which in its turn dictates the framework for the development of criteria for ascertainment of death. In this connection it is of interest that the Royal College of Physicians recently agreed the following definition of death: "The irreversible loss of the capacity for consciousness combined with irreversible loss of the capacity to breathe", and stated that "brain stem death is equivalent to the death of the individual". ${ }^{23}$ Pallis is correct to assert that all death is, and always has been, brain death. ${ }^{24}$ There is an urgent consequential need for parliament to legislate a definition of death in English law to this effect - this should not be left by default to the judges to develop. United States and Australian state statutes with dual, disjunctive concepts of death mislead and suggest, as many critics have argued, that death means different things in different contexts. It is essential that no perception develop generally in society that the notion of death is being manipulated solely in the transplant context. The detrimental consequences of such a perception would hugely outweigh any short-term benefit to society and to those awaiting organs for transplantation. At the same time, the dichotomy between the diagnosis of death and the time of death requires clarification. If a patient is not actually dead until two sets of brain stem death tests are carried out, as the code suggests, then the patient is still alive up until that point. No procedures should therefore be carried out which are not in the patient's best interests, such as those designed solely to preserve the viability and quality of a potential transplant organ. This would fall foul of the same proscription as EV, ie that it constitutes an unlawful battery. If the second set of tests are confirmatory instead, then such procedures may be permissible, because the individual is dead.

The criteria needed to establish brain death will still inevitably include the irreversible cessation of cardiopulmonary function - this is an integral feature of medically accepted criteria, employed in virtually all deaths occurring outside hospital. The necessar period of cessation should reflect the consensurs within the medical profession (not just the transplan community) and attract public confidence. The criteria (including any agreed time period) might be published in a revised and discrete code dealing wit the determination of death in general, applicable physicians in the community as well as to hospita doctors involved in transplantation practices or othe erwise. The latter scenario may attract the attentio $\vec{B}$ of commentators but is a good deal more public and transparent than the former.

David Price is Principal Lecturer in Law at the Dis Montfort University, Leicester, teaching and researching medical and criminal law. He is Co-Director of tho EUROTOLD research project on organ transplantationt funded by the European Commission. Address for readers' correspondence: School of Law, De Montfo University, The Gateway, Leicester, LE1 9BH.

\section{References}

1 Feest T, Riad H, Collins C, Golby M, Nicholls A, Hamad S. Protocol for increasing organ donation aftey cerebrovascular deaths in a district general hospita Lancet 1990; 335: 1133-5.

2 NHS Executive HSG(94)41: 1994 Oct. New Soloman M, Dingwall R, McHale J. A question of give and take. Improving the supply of donor organs for transplant $\Theta$ tion. King's Fund Institute: research report 18, 1994. $\overrightarrow{\vec{T}}$

3 Price D. Contemporary transplantation initiatives where's the harm in them?. Fournal of Law, Medicine and Ethics 1996; 24,2 139-49.

4 Shaw A. Non-therapeutic (elective) ventilation of potential organ donors: the ethical basis for changin the law. Fournal of Medical Ethics 1996; 22: 72-7.

5 [1987] Fleet Street Reports 90.

6 [1992] 3 Medical Law Reports 303.

7 [1993] 1 All England Reports 821.

8 Riad $\mathrm{H}$ The Exeter Protocol for elective ventilation. British Transplantation Society Newsletter 1994 Jun: 3-4곡

9 Working Party of the Health Departments of Great Britain and Northern Ireland. Cadaveric organs transplantation: a code of practice including the diagnosis $\overline{\overline{R F}}$ brain death, 1983. London: Health Departments $\Phi$ Great Britain and Northern Ireland, 1983. Healub Departments of Great Britain and Northern Irelands Memorandum on the diagnosis of death, 19790. London:Health Departments of Great Britain an Northern Ireland, 1979: para 6.

10 Arnold R, Youngner S, Schapiro R, Mason Spicer \& eds. Procuring organs for transplant: the debate over non heart-beating cadaver protocols. Baltimore: Johno Hopkins University Press, 1995.

11 Mason J, McCall Smith A. Law and medical ethig London: Butterworths, 1994: 281.

12 Tomlinson T. The irreversibility of death: reply $\frac{00}{0}$ Cole. Kennedy Institute of Ethics fournal 1993; 3, 157-165.

13 Cole D. Statutory definitions of death and the manage ment of terminally ill patients who may become organ. donors after death. Kennedy Institute of Ethics fourng 1993; 3,2: 145-155. 
14 Catherwood J. Rosencrantz and Guildenstern are 'dead'?. Fournal of Medical Ethics 1992; 18: 34-9.

15 Riad H, Nicholls A. Elective ventilation of potential organ donors. British Medical fournal 1995; 310: 714-5.

16 Jones $M$. Elective ventilation of potential organ donors. The legal background. British Medical fournal 1995; 310: 717-8.

17 Lynn J. Are the patients who become organ donors under the Pittsburgh protocol for "non-heart-beating donors" really dead?. Kennedy Institute of Ethics foumal 1993; 3,2: 167-178.

18 Working Party Report of the British Paediatric Association. Diagnosis of brain stem death in infants and children. London: British Paediatric Association, 1991.
19 [1981] 2 All England Reports 422.

20 Kennedy I, Grubb A. Medical law: text with materials. London: Butterworths, 1994: 1400.

21 Maastricht symposium on non-heart beating donors. Transplantation Proceedings 1995; 27,5: 2891-2939.

22 President's Commission for the Study of Ethical Problems in Medicine and Biomedical and Behavioral Research. Guidelines for the determination of death. Defining death. Washington: US Government Printing Office, 1981.

23 Royal College of Physicians Working Group. Criteria for the diagnosis of brain stem death. Fournal of the Royal College of Physicians of London 1995; 29: 381-2.

24 Pallis C, Harley D. ABC of brain stem death. London: BMJ Publications, 1996. 